\title{
Chapter 3 \\ Colorectal Cancer Disparities in Latinos: Genes vs. Environment
}

\author{
Maria Gonzalez-Pons and Marcia Cruz-Correa
}

\section{Overview of Colorectal Cancer Disparities in Hispanics}

For many years, science has been moving toward a better understanding of factors that contribute to colorectal cancer (CRC) health disparities. In 2012, CRC was the third most diagnosed cancer (1.4 million cases) and the fourth most common cause of cancer-related death causing 694,000 deaths worldwide [1]. An analysis of Globocan 2012 data shows that among countries in the Americas with the highest age-standardized rates (ASR) for CRC incidence, Canada ranks first with the highest ASR, closely followed by the United States (US) and Puerto Rico which rank fourth and fifth, respectively [1]. In the US, CRC is the third most commonly diagnosed malignancy and the third leading cause of cancer-related death [2]; however, marked differences in incidence and mortality have been noted among racial/ethnic groups [3].

It is important to note that US mainland Hispanics comprise a heterogeneous group of Hispanic subgroups from various countries in Central and South America. Hispanics are the result of more than 500 years of admixture of European, Indigenous American, and African individuals [4], and the extent of admixture varies according to the country of origin. CRC incidence rates among US mainland Hispanics also vary according to their country of origin, which supports the hypothesis that

\footnotetext{
M. Gonzalez-Pons

University of Puerto Rico Comprehensive Cancer Center, San Juan, PR, Puerto Rico

e-mail: mgonzalez@cccupr.edu

M. Cruz-Correa $(\bowtie)$

University of Puerto Rico Comprehensive Cancer Center, San Juan, PR, Puerto Rico

Departments of Medicine, Biochemistry and Surgery, University of Puerto Rico Medical Sciences Campus, San Juan, PR, Puerto Rico

Department of Medicine, Johns Hopkins University, Baltimore, MD, USA

e-mail: marcia.cruz1@upr.edu
} 
differences in ancestry may contribute to the variability of $\mathrm{CRC}$ incidence. Moreover, after Hispanic subgroups move to the US, the CRC incidence among them is higher than in their native country, supporting the idea that interactions between ancestry and environmental exposures resulting from acculturation are a major risk factor for the development of CRC [5]. Disparities in the age of onset of CRC have been reported between Hispanic subgroups. From 1993 to 2007, the overall incidence of CRC declined in Hispanics, but a dramatic 45\% increase was reported among Hispanics younger than 50 years of age (early-onset CRC) [6]. The increase in incidence of early-onset CRC was markedly greater in Hispanics than in nonHispanic Whites (NHW) and African Americans (AA), which increased 27\% and $15 \%$, respectively [6]. In a study investigating the demographic and clinical characteristics of 36,133 US mainland Hispanics with CRC living in California during 1995-2011, differences were observed in age at diagnosis according to the country of origin [7]. A statistically significant higher number of early-onset CRC was diagnosed in Hispanics (16\%) compared to NHW (7\%). Mexican and Puerto Rican Hispanics (PRH) were among the subgroups with the highest proportion of CRC cases among individuals $<50$ years old ( $20 \%$ and $9 \%$, respectively). When comparing all Hispanic subgroups with NHW, a higher number of Hispanics were diagnosed at advanced stages.

\section{Factors Contributing to Colorectal Cancer Disparities in Puerto Rican Hispanics}

In order to better understand CRC health disparities in Puerto Rico, our research team has worked on various transdisciplinary projects examining the epidemiological, environmental, and genetic factors that contribute to the CRC health inequities observed in this population.

\section{Epidemiology}

In a comparison of age-adjusted CRC incidence in the US and Puerto Rico from 2009 to 2013, AA and PRH men had the highest rates with 59.2 and 51.6 per 100,000 , respectively. US mainland Hispanic men had the second lowest ageadjusted CRC incidence rates during the same time period. However, in a comparison of age-adjusted CRC incidence rates among women during the same time period, AA women had markedly higher rates $(44.8$ per 100,000$)$ than the other racial/ethnic groups ( $<36.8$ per 100,000). A comparison of age-adjusted CRC mortality rates during the same time period shows a similar trend among AA and PRH men, who had the two highest mortality rates; however, age-adjusted mortality rates are comparable among women in all racial/ethnic groups. We recently reported the 
baseline CRC survival for PRH living in Puerto Rico [8]. Our study compared relative survival rates to those from racial/ethnic groups in the US, and found that PRH had the lowest survival rates in regional cancers and were the only racial/ethnic group in which there was a marked 5-year survival advantage among females (66.0\%) compared to males (60.3\%). Similar to the findings reported in California, $9.0 \%$ of the total CRC cases and $6.7 \%$ of total CRC deaths correspond to patients with early-onset CRC in Puerto Rico. These are nearly twice the percentages reported in the overall US population, thereby demonstrating a high burden of earlyonset CRC in Puerto Rico [9]. Moreover, a comparison of 5-year survivorship according to age at CRC diagnosis during 2005-2010 showed that early-onset CRC patients in Puerto Rico had worse survival (57\%) than CRC patients diagnosed at $50-64$ years $(66 \%)$ and $\geq 65$ years of age (62\%) [10]. In this same study, 5-year survival was also analyzed according to the type of health insurance coverage (government vs. non-government health plan). When combining all age groups, CRC diagnosis at advanced stages was more common in patients with the government health plan than those with non-government plans ( $44.3 \%$ vs. $40.2 \%$ diagnosed at regional stages, and $13.6 \%$ vs. $10.4 \%$ diagnosed at distant stages, respectively). Patients with the government health plan aged 50-64 (RR = 6.59; CI: 2.85-15.24) and $\geq 65$ ( $R R=2.4 ; C I: 1.72-4.04$ ) years were at greater excess risk of death than patients with non-government health plans.

\section{Environmental Factors}

CRC still remains a major public health problem. However, very few CRC prevention strategies are available other than routine screening. In addition to genomic alterations, dietary and environmental factors are believed to contribute to colorectal carcinogenesis [11]. Factors that may increase the risk of CRC include physical inactivity, obesity, alcohol consumption, smoking, gut microbiome composition, and diet [12]. Dietary patterns are widely believed to act as pro- and anti-tumor risk modifiers across the entire multistep process of colorectal carcinogenesis, and they have also been shown to have a pivotal role in modulating the gut microbiota [13, 14]. Moreover, in 2015 the International Agency for Research on Cancer (IARC) concluded that high red meat consumption is a risk factor for CRC [15].

Accumulating evidence supports the hypothesis that changes in gut microbiota composition may contribute to the development of CRC [16], but the specific mechanisms by which the gut microbiota contribute to colorectal carcinogenesis are not fully understood. Differences in gut microbiota composition among ethnic/racial groups, as well as between African American and rural Africans, have been reported $[17,18]$. Differences in bacterial community profiles and metabolites have been studied, but in our laboratory we are spearheading a study evaluating the association between dietary patterns, presence of bacterial toxins in stool and colonic mucosa, and colorectal neoplasia. Using a case-control study design, we examined the association between the presence of bacterial toxin genes ( $p k s, t c p C$, gelE, cnf-1, murB, 
and $u s p$ ) in stool and colorectal neoplasia using samples from individuals from the US and Puerto Rico [19]. These bacterial toxins promote inflammation, cell proliferation, and/or DNA damage, all of which are hallmarks of cancer. Differences were observed in the prevalence of these bacterial toxin genes between stool samples from individuals in the US and Puerto Rico. Moreover, stronger associations were observed between the presence of $>2$ bacterial toxin genes in stool and the likelihood of having colorectal neoplasia in PRH. In stool samples from the mainland US, individuals with $\geq 2$ of the genes in the panel were 9.33 times more likely to have colorectal neoplasia than individuals without these bacterial toxin genes. PRH individuals with $\geq 2$ of the genes were 11.3 times more likely to have colorectal neoplasia and 24 times more likely to have colorectal adenomas than individuals without these bacterial genes.

\section{Genetics}

Significant advances have been made toward a better understanding of the molecular landscape of colorectal tumors. The TCGA's effort is significant because it provides a comprehensive molecular characterization of tumors from the colon and rectum, and this study demonstrated the molecular similarities between colorectal tumors regardless of their location (colon vs. rectum) [20]. In this genome-scale analysis of 276 samples, $16 \%$ of colorectal carcinomas were found to be hypermutated. Although a wealth of molecular information is available on the tumors included in the TCGA, it is important to note that there are very few tumors from ethnic/racial minorities (12\% Black, 3\% Asian, and 3\% Hispanic) [21]. To better understand the molecular pathways that may contribute to the CRC health disparities observed among Hispanics, our group analyzed somatic molecular markers in PRH tumors $(n=488)$. We found that most tumors were microsatellite stable (98.4\%), CIMP-low (92.1\%), and had wild-type KRAS (68.8\%) and BRAF (90.8\%) genes. When compared to other US ethnic/racial groups, Hispanic CRC tumors had a lower percentage of microsatellite instability (MSI), lower incidence of CIMPhigh tumors, and lower mutation rates for both the KRAS and BRAF genes. A recent genome-wide association study (GWAS) reported 17 variants across four independent regions that merit further investigation because of suggestive CRC associations [22]. There is limited information regarding ethnic-specific risk variation in Hispanics. Our group recently collaborated with colleagues at the National Cancer Institute in order to elucidate risk variants for CRC among PRH. In another effort to understand germline genetic predisposition for CRC among Puerto Ricans, we spearheaded a study evaluating the association between ancestry and increased cancer risk in 425 controls, 99 adenomas, and 414 CRC cases. Previous studies reported that Hispanics with adenomas and CRC have higher African mean ancestry; positive associations between African ancestry and adenomas were observed [23]. However, in our PRH cohort, we observed a trend of increased risk of CRC with increasing levels of European ancestry. Puerto Rican individuals with higher 
than mean levels of West African ancestry were at increased risk of presenting with CRC tumors that are located in the distal colon, had moderate or low differentiation, and had BRAF mutations. Individuals who consumed high amounts of processed meat had 2 times higher CRC risk regardless of genetic ancestry.

\section{Summary}

- CRC health disparities have been reported among Hispanic subgroups, including PRH.

- CRC is the leading cause of cancer death in Puerto Rico. PRH had the lowest survival rates in regional cancers and were the only racial/ethnic group where a marked 5-year survival advantage was observed among females $(66.0 \%)$ compared to males $(60.3 \%)$.

- Marked disparities were observed according to age at CRC diagnosis and type of medical insurance within the Puerto Rican population.

- Dietary patterns are widely believed to act as pro- and anti-tumor risk modifiers across the entire multistep process of colorectal carcinogenesis and also play a pivotal role in modulating the gut microbiota.

- Differences were observed in the prevalence of bacterial toxin genes between stool samples from individuals in the US and Puerto Rico. Associations between having $\geq 2$ bacterial toxin genes in stool and the likelihood of having colorectal neoplasia were stronger among PRH.

- PRH colorectal tumors were mostly microsatellite stable (98.4\%), CIMP-low (92.1\%), and had wild-type KRAS (68.8\%) and BRAF $(90.8 \%)$ genes. When compared to other US ethnic/racial groups, PRH CRC tumors had a lower percentage of MSI, lower incidence of CIMP-high tumors, and lower mutation rates for both the KRAS and BRAF genes.

- In our PRH cohort, we observed a trend of increased risk of CRC with increasing levels of European ancestry.

\section{References}

1. Cancer Incidence and Mortality Worldwide: IARC CancerBase No. 11 [database on the Internet]. International Agency for Research on Cancer. 2012. Retrieved March 1, 2017, from http://globocan.iarc.fr

2. Siegel RL, Miller KD, Jemal A. Cancer statistics, 2018. Cancer J Clin. 2018;68(1):7-30. https://doi.org/10.3322/caac.21442.

3. Stefanidis D, Pollock BH, Miranda J, Wong A, Sharkey FE, Rousseau DL, et al. Colorectal cancer in Hispanics: a population at risk for earlier onset, advanced disease, and decreased survival. Am J Clin Oncol. 2006;29(2):123-6. https://doi.org/10.1097/01.coc.0000199918.31226. f8. 00000421-200604000-00003 [pii]. 
4. Salari K, Choudhry S, Tang H, Naqvi M, Lind D, Avila PC, et al. Genetic admixture and asthma-related phenotypes in Mexican American and Puerto Rican asthmatics. Genet Epidemiol. 2005;29(1):76-86. https://doi.org/10.1002/gepi.20079.

5. Pinheiro PS, Sherman RL, Trapido EJ, Fleming LE, Huang Y, Gomez-Marin O, et al. Cancer incidence in first generation U.S. Hispanics: Cubans, Mexicans, Puerto Ricans, and new Latinos. Cancer Epidemiol Biomarkers Prev. 2009;18(8):2162-9. https://doi.org/10.1158/1055-9965. EPI-09-0329.

6. Jafri NS, Gould M, El-Serag HB, Duan Z, Davila JA. Incidence and survival of colorectal cancer among Hispanics in the United States: a population-based study. Dig Dis Sci. 2012;58:2052. https://doi.org/10.1007/s10620-012-2454-3.

7. Stern MC, Zhang J, Lee E, Deapen D, Liu L. Disparities in colorectal cancer incidence among Latino subpopulations in California defined by country of origin. Cancer Causes Control. 2016;27(2):147-55. https://doi.org/10.1007/s10552-015-0691-4.

8. Gonzalez-Pons M, Torres M, Perez J, Velez A, Betancourt JP, Marcano L, et al. Colorectal cancer survival disparities among Puerto Rican Hispanics: a comparison to racial/ethnic groups in the United States. Cancer Clin Oncol. 2016;5(2):29-37. https://doi.org/10.5539/cco.v5n2p29.

9. Figueroa-Vallés NR, Ortiz-Ortiz K, Pérez-Ríos N, Villanueva-Rosa E, Traverso-Ortiz M, Torres-Cintrón CR, Suárez-Ramos T. Cancer in Puerto Rico, 2004-2009. San Juan: Puerto Rico Central Cancer Registry; 2012.

10. Ortiz-Ortiz KJ, Ramirez-Garcia R, Cruz-Correa M, Rios-Gonzalez MY, Ortiz AP. Effects of type of health insurance coverage on colorectal cancer survival in Puerto Rico: a populationbased study. PLoS One. 2014;9(5):e96746. https://doi.org/10.1371/journal.pone.0096746.

11. Shussman N, Wexner SD. Colorectal polyps and polyposis syndromes. Gastroenterol Rep (Oxford). 2014;2(1):1-15. https://doi.org/10.1093/gastro/got041.

12. American Cancer Society. Colorectal cancer facts \& figures 2014-2016. Atlanta: American Cancer Society; 2014.

13. Albenberg LG, Wu GD. Diet and the intestinal microbiome: associations, functions, and implications for health and disease. Gastroenterology. 2014;146(6):1564-72. https://doi. org/10.1053/j.gastro.2014.01.058.

14. Giovannucci E, Willett WC. Dietary factors and risk of colon cancer. Ann Med. 1994;26(6):443-52.

15. Bouvard V, Loomis D, Guyton KZ, Grosse Y, Ghissassi FE, Benbrahim-Tallaa L, et al. Carcinogenicity of consumption of red and processed meat. Lancet Oncol. 2015;16(16):1599600. https://doi.org/10.1016/S1470-2045(15)00444-1.

16. Gao Z, Guo B, Gao R, Zhu Q, Qin H. Microbiota disbiosis is associated with colorectal cancer. Front Microbiol. 2015;6:20. https://doi.org/10.3389/fmicb.2015.00020.

17. Ou J, Carbonero F, Zoetendal EG, DeLany JP, Wang M, Newton K, et al. Diet, microbiota, and microbial metabolites in colon cancer risk in rural Africans and African Americans. Am J Clin Nutr. 2013;98(1):111-20. https://doi.org/10.3945/ajcn.112.056689.

18. Gupta VK, Paul S, Dutta C. Geography, ethnicity or subsistence-specific variations in human microbiome composition and diversity. Front Microbiol. 2017;8:1162. https://doi.org/10.3389/ fmicb.2017.01162.

19. Gómez-Moreno R, González-Pons M, Soto-Salgado M, Cruz-Correa M, Baerga-Ortiz A. The Presence of Gut Microbial Genes Encoding Bacterial Genotoxins or Pro-Inflammatory Factors in Stool Samples from Individuals with Colorectal Neoplasia. Diseases. 2019 Feb 1;7(1). pii: E16. https://doi.org/10.3390/diseases7010016.

20. Cancer Genome Atlas N. Comprehensive molecular characterization of human colon and rectal cancer. Nature. 2012;487(7407):330-7. https://doi.org/10.1038/nature11252.

21. Spratt DE, Chan T, Waldron L, Speers C, Feng FY, Ogunwobi OO, et al. Racial/ethnic disparities in genomic sequencing. JAMA Oncol. 2016;2(8):1070-4. https://doi.org/10.1001/ jamaoncol.2016.1854. 
22. Schmit SL, Schumacher FR, Edlund CK, Conti DV, Ihenacho U, Wan P, et al. Genome-wide association study of colorectal cancer in Hispanics. Carcinogenesis. 2016;37(6):547-56. https://doi.org/10.1093/carcin/bgw046.

23. Hernandez-Suarez G, Sanabria MC, Serrano M, Herran OF, Perez J, Plata JL, et al. Genetic ancestry is associated with colorectal adenomas and adenocarcinomas in Latino populations. Eur J Hum Genet. 2014;22(10):1208-16. https://doi.org/10.1038/ejhg.2013.310.

Open Access This chapter is licensed under the terms of the Creative Commons AttributionNonCommercial 4.0 International License (http://creativecommons.org/licenses/by-nc/4.0/), which permits any noncommercial use, sharing, adaptation, distribution and reproduction in any medium or format, as long as you give appropriate credit to the original author(s) and the source, provide a link to the Creative Commons license and indicate if changes were made.

The images or other third party material in this chapter are included in the chapter's Creative Commons license, unless indicated otherwise in a credit line to the material. If material is not included in the chapter's Creative Commons license and your intended use is not permitted by statutory regulation or exceeds the permitted use, you will need to obtain permission directly from the copyright holder.

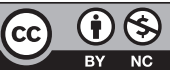

